IDEAS IN ECRLGGY AND EVRLUTION 3: 8-10, 2010

doi:10.4033/iee.2010.3.2.c

(C) 2010 The Author. (C) Ideas in Ecology and Evolution 2010

Received 3 February 2010; Accepted 5 February 2010

\title{
Commentary
}

\section{Youth and the tragedy of the reviewer commons}

\author{
Michael E. Hochberg \\ M.E. Hochberg (mhochber@univ-montp2.fr), Institute des Sciences de l'Evolution, Université Montpellier II, Place \\ Eugène Bataillon, CC065, 34095 Montpellier, France
}

Peer review is the main way that the scientific community certifies exposure. Peer review is by no means perfect (Smith 2006) - most journals adhere to norms of obtaining 1 to 3 reviews, which is a (very) small sample of the range of opinions and expertise in the community. Peer review, however, remains the best approach for journals to judge the merits of scientific research, and to provide feedback for authors to ameliorate the science, analysis, and inference of their work.

There are numerous challenges to the standards and application of peer review (Hames 2007). Together with colleagues, I recently argued that the scientific community is now faced with a "Tragedy of the reviewer commons": this is the increasing difficulty journals face in obtaining expert reviews due to the overexploitation of the reviewer pool (Hochberg et al. 2009). The Tragedy emerges from four main factors. First, many if not most journals receive increasing numbers of submissions through time, but do not increase the number of accepted articles proportionally. Second, journals solicit some reviewers (much) more than others. This is in part due to how editors perceive the quality of reviewer reports, speed, and areas of expertise. Third, individual reviewers may be solicited by many different journals, and because both (1) journals manage their own databases so as not to overburden reviewers, and (2) there is no intercommunication between journals, this leads to a (unbeknown to editors) cumulative burden on some reviewers. And fourth, top journals in ecology and evolution typically reject $50 \%$ or more of submissions (Aarssen et al. 2008), meaning that the average article, once published, may have been submitted to 2 or 3 journals, and have received 5 to 10 assessments. Authors are free to use or to ignore reviewer comments if their manuscript is flatly rejected, and most journals do not have clear policies for the transfer of reports from recent rejections.

The Tragedy brings with it several changes in the way we publish and, more worryingly, could change how we do science. First, journals (in making decisions) and authors (in revising their written work) will rely on an increasingly small, but willing, pool of reviewers. A smaller pool of reviewers means less diversity of perspective, and more skewed distributions of influence in informing editors for making publication decisions. Second, journals may need to adopt more active policies for encouraging or enforcing review, such as providing rewards (Aarssen and Lortie 2009) or punishing through sanctions (Hauer and Fehr 2007). The latter is particularly difficult to apply both administratively and morally, and I suspect that most journals will not adopt the latter policy, only do so either as a last resort, or if other journals adopt it as well. Third, we will likely see a shift in submissions towards journals that either minimally review, or do not review at all. This is already happening, with certain journals obtaining review(s) from editors only, or not soliciting peer reviews, but rather encouraging the scientific community to comment on posted articles.

I believe that this third effect presents the greatest challenge, since it lifts the peer review screen on the communicative and scientific qualities of published science, and, through time, risks creating deterioration in these norms. Science is not a fixed practice, it evolves. I advocate the view that the evolution of science follows many of the same principles of Darwinian natural selection. Evolution will be adaptive insofar as some degree of guiding selection is imposed. Whence, reducing or eliminating peer review carries the risk of increasingly seeing sloppy science published alongside of excellent science. The current generation of 
scientists can discern the two, but given that the philosophy, culture, communication and techniques of science are transmitted to a considerable extent through teaching and published work, I am concerned that future generations may become increasingly permissive.

From the above arguments, there would appear to be a limited number of options available to curb the Tragedy: increase the size of reviewer databases, more evenly distribute the burden, send fewer papers out for external review, screen potential submissions by charging a fee, impose sanctions on scientists who shirk their responsibility, and give rewards to those who pull their weight and conduct insightful, thoughtful reviews within the time limits set by the journal.

Management of the commons in the ecological and evolutionary sciences is in its early days, and of the above cited options, two are currently, routinely employed. First, many journals reject manuscripts without external review. These rejection rates vary (probably considerably) from journal to journal, and few proposals have been made as to how this practice can be quantified and optimized (Allesina 2009), in particular, with the dual aims of externally assessing a maximum of submissions, whilst sustaining the reviewer database. Second, journals seek alternative reviewers if those of choice do not accept to review manuscripts, or are not invited in the first place because they appear to be overburdened. This includes asking editorial board members to assess submissions in the place of external reviewers, and sometimes obtaining fewer reports than usual on submissions. These practices certainly slow the Tragedy, but at the cost of penalizing at least some good science by not externally assessing it to the highest standards.

Donaldson and colleagues (2010) give new insight by suggesting that many journals overlook the potential of employing graduate students, post-graduate students, and postdoctoral scientists as reviewers. The numbers of these younger scientists may indeed be staggering compared to established professionals, and as such, the former constitute a considerable resource to achieve systematic peer review. Students and young professionals also have the advantage, according to Donaldson and colleagues, of being more enthusiastic about the review process and less burdened with administrative duties than more established scientists. Finally, employing this human capital is a healthy, positive way forward, because established scientists would teach the younger generation on how to conduct manuscript assessments. This would, moreover, provide a unique angle for teaching young scientists how to improve their own science through the close examination of the strengths and weaknesses of colleagues' work.

As Donaldson and colleagues acknowledge, soliciting reviews from less experienced researchers has several quality risks. These include the presentation of the report, the levels of criticism and detail, and scientific scholarship. Editors are well aware of these in administrating journals, but I believe that special attention and specific accommodations are absolutely necessary if journals are to formally adopt Donaldson et al's proposal. First, editorial boards need to be sensitive to the importance of soliciting younger scientists to conduct assessments. Journal databases need to make explicit reviewers' education level and previous reviewing experience. Many journals now have grading systems for assessing the appropriateness of their reviewers. Second, many editors will be unfamiliar with the names and expertise of younger investigators. Databases will need to be actively ameliorated as a consequence. Third, supervisors and mentors need to take an active role in educating would-be young reviewers, and take responsibility vis-à-vis journal editors for submitted reports. The latter point is particularly important, since it is the contextual oversight that ensures quality, scholarship and constructiveness. This responsibility is part of the collective action necessary for effective peer review and will contribute to the future sustainability of the commons.

\section{References}

Aarssen, L.W., Tregenza, T., Budden, A.E., Lortie, C.J., Koricheva, J. and R. Leimu. 2008. Bang for your buck: rejection rates and impact factors in ecological journals. The Open Ecology Journal 1: 14-19. CrossRef

Aarssen, L.W. and C.J. Lortie. 2009. Ending elitism in peer-review publication. Ideas in Ecology and Evolution 2: 18-20. CrossRef

Allesina, S. 2009. Accelerating the pace of discovery by changing the peer review algorithm. arXiv:0911.0344v1.

Donaldson, M.R., Hasler, C.T., Hanson, K.C., Clark, T.D., Hinch, S.G. and S.J. Cooke. 2010. Injecting youth into peer-review to ensure its sustainability: a case study of ecology journals. Ideas in Ecology and Evolution 3: 1-7. CrossRef

Hames, I. 2007. Peer Review and Manuscript Management in Scientific Journals: Guideline for Good Practice. Blackwell Publishing. CrossRef

Hauser, M. and E. Fehr. 2007. An incentive solution to the peer review problem. PLoS Biology 5: e107. CrossRef

Hochberg, M.E., Chase, J.M., Gotelli, N.J., Hastings, A. and S. Naeem. 2009. The tragedy of the reviewer commons. Ecology Letters 12: 2-4. $\underline{\text { CrossRef }}$

McPeek, M.A., DeAngelis, D.L., Shaw, R.G., Moore, A.J., Rausher, M.D., Strong, D.R., Ellison, A.M., Barrett, L., Rieseberg, L., Breed, M., Sullivan, J., Osenberg, C.W., Holyoak, M. and M.A. Elgar. 
2009. The golden rule of reviewing. The American Naturalist 173: E155-E158. CrossRef

Smith, R. 2006. Peer review: a flawed process at the heart of science and journals. Journal of the Royal Society of Medicine 99: 178-182. CrossRef 